\title{
THE INFLUENCE OF ORGANIC IIQUIDS UPON THE INTERACTION OF HYDROGEN SULPHIDE AND SULPHUR DIOXIDE
}

\author{
BY DAVID KLEIN
}

\section{Introduction}

Numerous examples of the influence of slight amounts of water upon chemical changes of various kinds are on record. But similar studies of the effect of liquids other than water are few and fragmentary. So it has seemed that a systematic investigation of the influence of organic liquids upon a gaseous system, incapable of decomposition in the dry state, would be of considerable value in gaining an understanding of the mechanism of chemical change, as well as in formulating a theory of solutions.

Because of its abundance, and its great solvent power (for some classes of substances), water is regarded by certain chemists as having exceptional properties. "Water is a substance whose presence in at least minute amounts seems to be essential to the occurrence of most chemical reactions. Moreover, its method of action is probably unique, consisting either in a hydration or electrolytic dissociation of the reacting substances. It is therefore not inappropriate that it

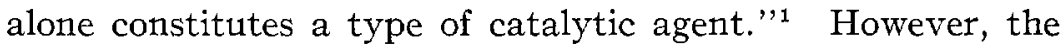
results of the present investigation clearly show, at least as far as one property of water is concerned, namely its ability to accelerate chemical changes, that other liquids have that characteristic in a no less marked degree.

The action between hydrogen sulphide and sulphur dioxide was selected as suitable for an experimental investigation. It is difficult to state who first studied this reaction; certainly, it was known a century and a quarter ago. In I 8 I 2 Cluzel $^{2}$ discovered that the gaseous system would not be decomposed unless moisture is present. The gases after being

${ }^{1}$ Noyes and Sammet: Jour. Am. Chem. Soc., 24, 498 (1902).

${ }^{2}$ Cluzel: Ann. Chim. Phys., 84, I62 (1812). 
dried by fused calcium chloride were mixed in varying proportions in a glass container over mercury. Depending upon the degree of desiccation, the period of no action varied from fifteen minutes to five hours. Experiments conducted in the absence of sunlight, showed no difference in action, when compared with similar tests, performed in sunlight. Cluzel summarizes his work as follows: "Que l'hydrogène sulfuré et l'acide sulfureux peuvent rester assez longtemps en contact sans se décomposer, quand ils sont bien secs et qu'il est trèsprobable qu'ils ne se décomposeraient pas si on les faisait arriver très-secs dans un appareil où il ny êut aucun corps qui exersât une affinité sur le soufre."

Then, in $\mathrm{r} 868$, Schmidt ${ }^{1}$ published a note on the influence of moisture on the gaseous mixture: "Nachdem ich die Angabe Vogel's (Gmelin. Handb. 643), dass gewöhnliche Schwefelsaüre von Schwefelwasserstoff zersetzt wird, bestätigt, beobachtete ich die Bildung von schwefliger Saüre bei Übergiessen fein gepulverter oder gefällter Schwefelmetalle mit concentrirter Schwefelsaüre, so zwar, dass rauchende keinen oder nur ein Minimum won Schwefelwasserstoff auftreten lässt. Die fraglichen beiden Agentien vollkommen trocken gemischt, reagiren nicht auf einander; führt man in das Gefäss einen benetzten Glasstab, so zeichnen sich die berührten Stellen momentan durch ausgeschiedenen Schwefel und die Pentathionsaüre tritt auf."

\section{Apparatus and Method}

The experimental parts of this investigation may be conveniently divided among several general heads; (I) the preparation, drying and storing of the pure gases, (2) the devising of a suitable reaction vessel, (3) the preparation of pure dry organic liquids.

Hydrogen sulphide.-After many unsatisfactory trials

${ }^{1}$ W. Schmidt: Zeit. für Chemie (Beilstein-Fittig), Ir, 50 (I868). The University of Wisconsin does not possess this periodical; but a copy was kindly loaned by the Mass. Inst. of Technology, for which I herewith wish to express my gratitude. Since the article in question is not readily accessible, it was thought worth while to reprint it in full. 
with various substances for the preparation of pure hydrogen sulphide, such as calcium sulphide and antimony sulphide, it was found that the action of hydrochloric acid upon zinc sulphide would yield a very pure gas in quantities that were readily controlled. The means for drying and storing the gas are represented in Fig. I. The generator A was constructed out of a dropping funnel and a Liebig condenser jacket. It was filled in the inverted position through $a$, which was then sealed off. B is an ordinary wash bottle, containing pure water, to free the gas from any hydrochloric acid vapors. C, a large calcium chloride tower, was constructed from a

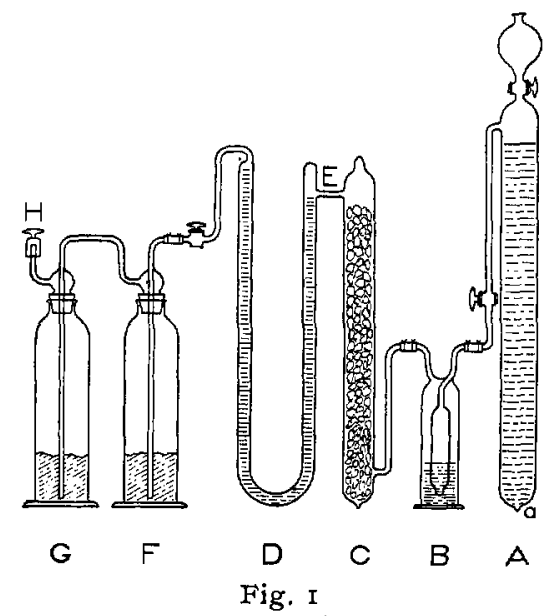

Liebig condenser jacket. $\mathrm{D}$ is a large U-tube, made by bending a glass tube $4^{\prime}$ long and ${ }^{5} / 8^{\prime \prime}$ in diameter. After being filled with phosphorus pentoxide, it was sealed to $\mathrm{C}$ at E. The dried gas was stored in two 500 cc Drechsel wash bottles $(\mathrm{F} * \mathrm{G})$ containing some phosphorus pentoxide. Some connections were made by sealing the tubes together, while others consisted of heavy rubber tubing. The latter gave no trouble, but, if necessary, could be eliminated.

The train was first exhausted by means of a water pump; then filled with the gas, by allowing concentrated hydrochloric acid to flow down from the dropping funnel. The 
exhaustion and refilling were repeated until the issuing gas was completely absorbed by a caustic potash solution.

Sulphur dioxide.-For the preparation of this gas concentrated hydrochloric acid was allowed to act on pure sodium acid sulphite, contained in the generator A (Fig. 2). Addi-

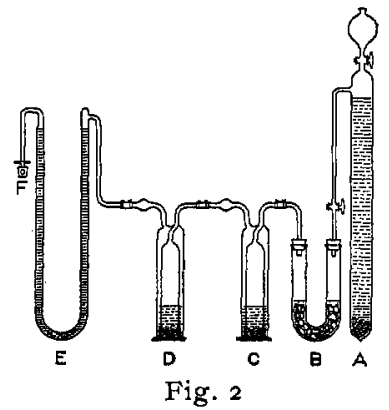

tional parts of the train were a wash bottle $\mathrm{B}$ containing pure water, to remove hydrochloric acid; two Wetzel bottles (C-D) capacity $500 \mathrm{cc}$; containing conc. sulphuric acid; a large U-tube $\mathrm{E}$ made by bending a glass tube $3^{\prime} \times{ }^{5} / \mathrm{s}^{\prime \prime}$, and filled with phosphorus pentoxide. It might be well to state at this point that all the phosphorus pentoxide used in these experiments was the ordinary variety, supplied either by Merck or Schuchardt.

Reaction vessel.-This was made out of a condenser jacket (300 cc) and stop-cocks (the ordinary two-way variety). (A. Fig. 3). Branch $c$ was connected with the sulphur

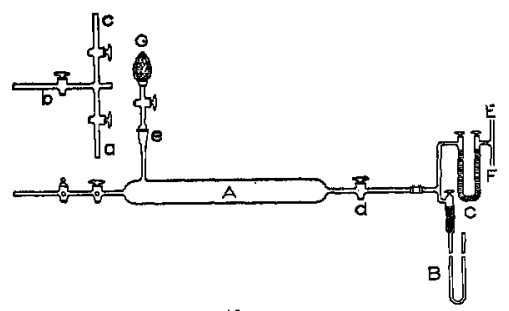

Fig. 3

dioxide generator; branch a likewise with the hydrogen sulphide train. Through $b$ a current of air, dried by sul- 
phuric acid and phosphorus pentoxide, was slowly aspirated by means of a water pump. The exit tube $d$ was protected from the moisture of the pump $\mathrm{E}$ by a six-inch Schwartz tube, containing phosphorus pentoxide. A second similar guard bulb was attached to the Sprengel pump F; while a third one was connected with the open manometer B. At $e$ is a ground glass joint, accurately fitted to the vessel $G$, which served as the receptacle for the pure organic liquid. The bulb was an ordinary $25 \mathrm{cc}$ acetylization flask, to which was sealed a stopcock. Connection of the reaction chamber to the various parts of the apparatus was made with thick-walled rubber tubing, the ends of the glass tubing being pushed as close together as possible.

The purification of the organic liquids was carried out as follows: In the first place, the purest sample of the particular liquid that the laboratory afforded, was subjected to ordinary fractional distillation. The desired portion was collected in an eight-ounce bottle (commonly known as a specimen bottle) provided with an accurately ground stopper. Previous to use, these bottles were thoroughly cleaned, rinsed with very pure distilled water, and dried in an air bath at $160^{\circ} \mathrm{C}$ for $3^{-5}$ hours. They were kept in a desiccator containing phosphorus pentoxide. The appropriate drying agent was added to the liquid, with which it remained in contact, with frequent shaking, for varying periods of time.

After each experiment the reaction vessel was coated with a film of sulphur. For the rapid and complete removal of this layer, fuming nitric acid was found very efficient. After being thoroughly rinsed with distilled water, the apparatus was steamed out, the steam being evolved from water to which sulphuric acid and potassium bichromate were added. Steam is a very delicate test for grease, since the latter supplies nuclei for the condensation of water vapor, thus causing drops to form on any unclean portion of the vessel. All visible moisture was removed by aspirating warm air through the apparatus. The stop-cocks and bores were 
carefully wiped with a clean, fat-free cloth, after which they were thinly coated with a rubber composition lubricant.

The lubricant is the one recommended by Travers. ${ }^{1}$ It was used in all experiments, excepting a few trials with phosphoric acid, made by exposing phosphorus pentoxide to the air. However, it was found that this substance would cause the gases to react, and was therefore discarded.

When the reaction vessel was cleaned, dried and set in position, the catalytic liquid was subjected to a final distillation. This was accomplished in the special apparatus, shown in Fig. 4. It consisted of a I 50 cc distilling flask $\mathrm{A}$ to which

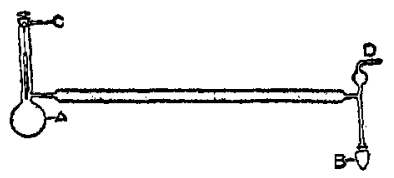

Fig. 4

was sealed a limb of a Schwartz tube. A condenser was also sealed to the flask. As a receiver B a $25 \mathrm{cc}$ acetylization flask was used, so chosen that its ground joint would fit very closely the small flask to be attached to the reaction chamber. To suspend a thermometer in the flask, a piece of fusible glass was bent so that the head could be inserted in the glass stopper, if held at an angle, but was too large to slip out if held vertically. From this hook a suitable thermometer was suspended by a platinum wire.

The distilling apparatus was thoroughly dried by drawing through it a current of air, that had passed through conc. sulphuric acid and phosphorus pentoxide. Tubes of the latter material also prevented the access of any moisture from the pump D. After the air had thus passed for several hours at ordinary temperatures, the apparatus was highly heated with a free Bunsen flame. Dry air was continually aspirated through $\mathrm{C}$, until room temperature was again restored. Then the stopper was quickly removed, the liquid poured in, and

1 "Study of Gases." 
distilled. After the condenser had been thoroughly moistened with the distilled liquid, the receiver was quickly replaced by the bulb which up to this time was kept in a desiccator over phosphorus pentoxide. When filled with the liquid, the bulb was very quickly detached and fitted with its own stopper, which was described before.

The bulb was attached to the reaction vessel. A current of dry air at room temperature, was drawn through the apparatus for hours (varying from 6 to 20), after which the drying was continued, while the apparatus was being highly heated with a free Bunsen flame. This last operation was continued for an hour. Then the reaction vessel was evacuated as far as possible by means of a water pump. To reduce the pressure as completely as possible, the final exhaustion was effected with a good sprengel pump. The pressure was noted on a closed manometer on the pump and also on an open manometer (B Fig. 3). To fill the vessel with the reacting gases in the proper proportion, sulphur dioxide was allowed to slowly enter until the pressure had risen to one-third the atmospheric pressure as read on the open manometer. The hydrogen sulphide was admitted, to make up the other twothirds. All stop-cocks were closed, so that the mixture was contained in an apparatus entirely of glass, except for the lubricant on the stop-cocks.

The mixture was allowed to remain an hour or more, to be sure that no action occurred spontaneously. Then by opening the stop-cocks to the catalyzer bulb (G Fig. 3) and gently warming the latter, enough liquid (never more than a few cc) could be admitted into the reaction chamber. The detailed observations will be given below.

Results.-Since the procedure in nearly all cases was essentially that given above, it is not necessary to repeat it in discussing the various liquids.

Benzol.-Some of Kahlbaum's recrystallized thiophenefree product was dried with phosphorus pentoxide for four months. In the first trial there was no action in three hours. A few drops of water were poured into the reaction vessel by 
quickly raising and replacing the catalyzer bulb. There was immediate action. Subsequently on opening tap $d$ (Fig. 3) under water, the liquid completely filled the vessel. In fact, this check upon the purity of the mixture was performed after each experiment.

The experiment was repeated with a new, freshly distilled sample of benzol, with the result that there was no action within an hour and thirty minutes.. ${ }^{1}$

Carbon tetrachloride.-The liquid was dried with phosphorus pentoxide for two weeks. Not the slightest sign of action within an hour. Repeated experiment, with a freshly distilled sample of the same liquid, with similar results.

Chloroform.-This was dried for three days with phosphorus pentoxide. It produced no action within an hour. A second trial gave the same result.

Ethyl alcohol.-OOrdinary alcohol was treated with calcium carbide, by boiling under a reflux condenser. The acetylene was removed by distilling under diminished pressure, and then by treating with bromine. The product was twice fractionated after adding sodium. As soon as the first drop of this liquid entered the reaction vessel, there was intense action.

A repetition of the experiment with a sample of this alcohol, after a third distillation with sodium, gave a similar result. After this experiment a very slight odor of acetylene was noticeable in the alcohol, so that the results were not conclusive, although, as will appear later, the action must be attributed to the alcohol.

A new sample was prepared as follows: Ordinary alcohol was boiled under a reflux condenser with pure lime for six hours; then distilled. It was similarly treated with barium oxide. $^{2}$ A final distillation was made after treatment with

${ }^{1}$ It must not be inferred that action occurred after this period. Here and elsewhere in this paper, where a similar expression occurs, it means that the experiment was discontinued at this point.

${ }^{2}$ I have found barium oxide, a most efficient drying agent. The easiest way to prepare a suitable product was to heat anhydrous barium peroxide to 
sodium. As in the two previous trials, the first drop caused instantaneous action.

Amylene.-A Schuchardt preparation was dried for three days over fused calcium chloride. The portion boiling between $40^{\circ}-4 \mathrm{I}^{\circ}$ was employed. There was no visible action in over an hour. A drop of water caused an immediate deposition of sulphur.

Acetone.-Merck's C. P. product was dried for four days with anhydrous sodium sulphate, before redistilling. Immediate action occurred as soon as the first drop entered the apparatus.

Repeated with a portion of the acetone that had remained in contact with the drying agent for two days longer. Similar results were obtained as in the preceding trial.

A third experiment was performed with a sample of Kahlbaum's acetone, that had been standing over fused calcium chloride for seven weeks. As in the other trials, the reaction began immediately.

Ether.-The material was obtained from Professor Koelker, who had rendered it absolute from the commercial variety by treatment with calcium chloride and then with sodium. It was further dried over sodium and distilled from a fresh portion of that metal. The reaction was rather slow at first, but in less than two minutes it proceeded rapidly, due in part at least, to autocatalysis.

The experiment was repeated after continued treatment with sodium, with similar results, as in the first trial.

Methyl cyanide.-Merck's product was redistilled after being dried with fused calcium chloride for five days. After treatment with phosphorus pentoxide for four days, it was again distilled. Throughout the manipulations, the liquid boiled very constantly. For thirty-five minutes, the liquid caused no action. Then the reaction vessel became coated with a light yellow deposit.

redness for an hour and then cool the product in a desiccator over phosphorus pentoxide. The mass was quickly pulverized and sealed in small portions in test tubes. 
Ethyl disulphide.-The sample was a Schuchardt preparation. It was a yellow, oily liquid with a very disagreeable odor. No attempt was made at purification. The liquid was simply poured into the dried catalyzer bulb. Even after an hour's contact, there was not the slightest sign of action. A few drops of water produced immediate reaction. After several hours a large portion of the sulphur had dissolved in the ethyl disulphide.

Carbon bisulphide.-Ordinary carbon bisulphide was purified by shaking for hours with mercury; then decanting and shaking with potassium permanganate. It was again decanted, and after further treatment with mercury, it was redistilled. In twenty-five minutes there was no visible change. Then the glass in the $T$ tube around the stop-cocks became coated with sulphur, although the liquid remained perfectly colorless and transparent. Of course, the action finally continued to completion.

The above experiment was repeated, after the carbon bisulphide had been further shaken with mercury. The same phenomena were noted as in the previous trial. During the first twenty-one minutes there was no action; then a distinct clouding of the $\mathrm{T}$ tube occurred, but the liquid remained clear.

A third trial with some carbon bisulphide that had been in contact with mercury for six months, gave no action in an hour and ten minutes. After that, the same clouding of the $T$ tube was observed, while the liquid remained clear.

From these experiments it was evident that the lubricant was a disturbing factor. To eliminate this source of trouble, a reaction chamber was constructed, similar to the one used in all other cases with the exception that no stop-cocks were used. Instead the tubes were constricted in order to seal them off.

The catalyzer was contained in a little glass bulb, which was placed in the apparatus before sealing on the $T$ tube. The obtaining of the liquid was necessarily different from the usual method. A receiver was devised, consisting of a large 
bulb and a small glass tube, each sealed to a branch of a $T$ tube. The third branch was sealed to a large adapter, which fitted over a two-hole stopper, to accommodate the condenser tube and a guard tube of phosphorus pentoxide. The condenser was pushed down into the adapter as far as possible, to avoid contact of the carbon bisulphide fumes with the rubber stopper. The receiver was packed in an ice-salt mixture. The idea of the peculiarly shaped receiver was that the distillate could first be collected in the large bulb, but when the desired fraction was obtained, it could be diverted into the small tube by slightly turning the receiver. When enough of the liquid was obtained, the small tube was sealed off.

As to the drying and filling of the apparatus, the manipulation was the same as in the other cases. After admitting the sulphur dioxide, the tube connecting the reaction vessel with the sulphur dioxide train was sealed off. In like manner the other tubes were sealed. A very slight deposition of sulphur occurred when the tube leading to the hydrogen sulphide train was sealed; but there was no visible increase in this deposit in forty-five minutes, probably because of slowness of diffusion in so small a tube.

The bulb containing the carbon bisulphide was broken by shaking the apparatus. There was no visible action in an hour and five minutes. Upon the supposition that the carbon bisulphide might have dissolved the sulphur as fast as it formed, the end of the apparatus was broken under mercury. There was no appreciable rise. Upon the admission of a few drops of water, immediate action ensued.

Ethyl chloride.-The material was the usual liquid employed for anaesthesia. It was contained in a sealed glass tube, which was broken and the contents were rapidly poured into the catalyzer container. A large portion of the liquid vaporized, but enough was secured for a fair trial. After forty-five minutes of contact, the liquid seemed not at all affected. A little more of it was forced into the reaction vessel, whereupon the pressure became so great as to violently force out the ground joint and break it. 
Benzoyl chloride.--A fresh unopened bottle of Kahlbaum's make was used as the catalyzer, without any special purification. The liquid was simply poured into the dried catalyzer container. There was no action in forty-five minutes. Water caused an immediate deposition of sulphur.

The experiment was repeated with the same liquid. There was no action in three and one-half hours.

Methyl benzoate.-A Schuchardt preparation was dried over fused calcium chloride for four days and then distilled under diminished pressure. For the first twenty-five minutes there was no action; then sulphur was rapidly deposited.

Acetyl chloride.-An unopened bottle of Merck's product was used without any attempt at purification. There was no reaction in two hours and twenty minutes. Water caused an immediate precipitation of sulphur.

Benzaldehyde.-A Schuchardt preparation was dried for four days over fused calcium chloride, after which it was distilled in a current of carbon dioxide under diminished pressure. Immediately after the admission of the catalyzer it assumed a greenish color, then a yellow one, and in a few minutes, sulphur was deposited.

Carvone.-This compound is of special interest, since it forms a definite crystalline compound with hydrogen sulphide. The material was labelled "Chemically Pure Carvol" Schimmel \& Company. The liquid was dried over anhydrous copper sulphate for three days. The portion boiling between $222^{\circ}-224^{\circ}$ was used. It had a very slight yellow tinge. There was instantaneous action as soon as the liquid entered the reaction chamber.

Benzyl cyanide.-A Schuchardt specimen was dried over anhydrous copper sulphate for four days. In less than two minutes, after it was admitted into the reaction vessel, there was formed a distinct yellow deposit.

Propyl acetate.-A Schuchardt sample had been standing for years over fused calcium chloride. Reaction ensued as soon as the liquid entered the reaction vessel.

Amyl alcohol.-A redistilled Kahlbaum preparation was 
dried over calcium chloride for two days and over anhydrous copper sulphate for six days. It boiled very constantly. There was instantaneous action when the liquid entered the catalyzer vessel.

The experiment was repeated with a different sample of Kahlbaum's make, that was refractionated and then dried over barium oxide for eight days. The barium oxide showed extremely little hydration, a state that was easy to detect, inasmuch as the anhydrous oxide was gray, while the hydrate was a pure white. As in the preceding trial, there was an instantaneous deposition of sulphur. The next morning many monoclinic sulphur crystals were noted in the amyl alcohol. This phenomenon is not anomalous, as other cases are on record of sulphur crystallizing in the monoclinic system at ordinary temperatures.

Propionitrile.-A good sample was dried for eight days over barium oxide. The drying material seemed unaffected. For the first seven minutes, after introducing the liquid, there was no visible action. Then the liquid became cloudy.

Isobutyl alcohol.-A redistilled Kahlbaum product was dried for five days over barium oxide. It distilled quite constantly. The liquid caused immediate, vigorous action. The experiment was repeated, using the above sample of the alcohol after it had remained over barium oxide for three days longer, and had then been treated with sodium. The boiling point was unchanged. Reaction proceeded exactly as in the previous trial.

Isobutyl acetate.-A redistilled Schuchardt preparation was dried over barium oxide for two weeks. For the first six minutes, after entering the reaction vessel the liquid remained transparent, then it became clouded, and soon a dense deposit of sulphur was formed.

Nitrobenzene.-A Schuchardt product was redistilled. It caused no action in an hour and forty-five minutes. Water produced an instantaneous precipitation.

Valeronitrile.-A good sample was refractionated; then dried for ten days over anhydrous copper sulphate and for two 
days over barium oxide. For the first fifteen minutes after admitting the liquid, there was no action. Then the liquid became cloudy.

Methyl ethyl ketone.-A previously unopened bottle of Schuchardt's make was dried for two days over barium oxide. In less than two minutes after entering the reaction vessel, the liquid clouded.

TABLE I

\begin{tabular}{|c|c|c|c|c|}
\hline & & Action & $\begin{array}{l}\text { Dielec- } \\
\text { tric } \\
\text { constant }\end{array}$ & $\begin{array}{l}\text { Associa- } \\
\text { tion } \\
\text { factor }\end{array}$ \\
\hline Water & & immediate & 80.0 & 3.60 \\
\hline Ethyl alcohol & $\mathrm{C}_{2} \mathrm{H}_{5} \mathrm{OH}$ & " & 25.8 & 2.74 \\
\hline Isobutyl alcohol & $\mathrm{C}_{3} \mathrm{H}_{7} \mathrm{OH}$ & “ & 20.0 & 1.95 \\
\hline Isoamyl alcohol & $\mathrm{C}_{5} \mathrm{H}_{11} \mathrm{OH}$ & “ & I6.0 & 1.97 \\
\hline Acetone & $\mathrm{CH}_{3} \mathrm{COCH}_{3}$ & 1 onth the & 25.0 & I. 26 \\
\hline Methyl ethyl ketone & $\mathrm{CH}_{3} \mathrm{COC}_{2} \mathrm{H}_{5}$ & less than two min. & 17.8 & I. I 5 \\
\hline Ace tonitrile & $\mathrm{CH}_{3} \mathrm{CN}$ & after I5 min. & 36.4 & 1.60 \\
\hline Propionitrile & $\mathrm{C}_{2} \mathrm{H}_{5} \mathrm{CN}$ & arter $7 \mathrm{~min}$. & 26.5 & 1.77 \\
\hline Valeronitrile & $\mathrm{C}_{4} \mathrm{H}_{9} \mathrm{CN}$ & arter $15 \mathrm{~mm}$. & 17.4 & - \\
\hline $\begin{array}{l}\text { Benzyl cyanide } \\
\text { Methyl benzoate }\end{array}$ & $\begin{array}{l}\mathrm{C}_{6} \mathrm{H}_{5} \mathrm{CH}_{2} \mathrm{CN} \\
\mathrm{C}_{6} \mathrm{H}_{5} \mathrm{COOCH}_{3}\end{array}$ & after 25 min. & $\begin{array}{r}14.9 \\
6.58\end{array}$ & - \\
\hline Propyl acetate & $\mathrm{CH}_{3} \mathrm{COOC}_{3} \mathrm{H}_{7}$ & immediate & 5.73 & - \\
\hline Isobutyl acetate & $\mathrm{CH}_{3} \mathrm{COOC}_{4} \mathrm{H}_{8}$ & after 6 miv. & 5.26 & - \\
\hline Ether & $\left(\mathrm{C}_{2} \mathrm{H}_{5}\right)_{2} \mathrm{O}$ & less than two min. & $4 \cdot 3$ & 1.04 \\
\hline Benzaldehyde & $\mathrm{C}_{6} \mathrm{H}_{5} \mathrm{CHO}$ & immediate & 17.7 & 0.97 \\
\hline Carvone & $\mathrm{C}_{10} \mathrm{H}_{14} \mathrm{O}$ & " " & $\longrightarrow$ & - \\
\hline Carbon bisulphide & $\mathrm{CS}_{2}$ & none & 2.64 & 1.67 \\
\hline Ethyl disulphide & $\left(\mathrm{C}_{2} \mathrm{H}_{5}\right)_{2} \mathrm{~S}_{2}$ & $" ،$ & 7.2 & 一 \\
\hline Benzol & $\mathrm{C}_{6} \mathrm{H}_{6}$ & 3 & 2.28 & I.OI \\
\hline Amylene & $\mathrm{C}_{5} \mathrm{H}_{10}$ & “" & 2.20 & 0.96 \\
\hline $\begin{array}{l}\text { Chloroform } \\
\text { Nitrobenzen }\end{array}$ & $\mathrm{CHCl}_{3}$ & " & $5 \cdot 14$ & 0.94 \\
\hline $\begin{array}{l}\text { Nitrobenzene } \\
\text { Acetyl chlorid }\end{array}$ & $\mathrm{C}_{6} \mathrm{H}_{5} \mathrm{NO}_{2}$ & “ & 36.45 & 0.93 \\
\hline $\begin{array}{l}\text { Acetyl chloride } \\
\text { Benzoyl chloride }\end{array}$ & $\mathrm{CH}_{3} \mathrm{COCl}$ & “ & $25 \cdot 30$ & 1.06 \\
\hline $\begin{array}{l}\text { Benzoyl chloride } \\
\text { Ethyl chloride }\end{array}$ & $\mathrm{C}_{6} \mathrm{H}_{5} \mathrm{COCl}$ & " & - & - \\
\hline $\begin{array}{l}\text { Ethyl chloride } \\
\text { Carbon tetrachloride }\end{array}$ & $\begin{array}{l}\mathrm{C}_{2} \mathrm{H}_{5} \mathrm{Cl} \\
\mathrm{CCl}_{4}\end{array}$ & “ & $\begin{array}{l}0.29 \\
2.25\end{array}$ & $\overline{1.0 I}$ \\
\hline
\end{tabular}

\section{Discussion}

The experiments have been reported in considerable detail, because the experience of the author with the work of other investigators along similar lines seemed to warrant it. Thus, the report of the classic work of Baker on ammonia 
and hydrochloric acid contains so little of the necessary manipulating directions that a repetition of his experiment is an extremely difficult matter.

Experimentation of the kind involved in this paper is always open to the general objection that the substances which induce action may not have been sufficiently dry or pure. Of course, this criticism is unanswerable. On the other hand, to maintain that the reacting substances were "absolutely dry," a phrase one frequently meets in the writings of reputable chemists, would require proof that could not be furnished. The best that can be done is to give an accurate and detailed description of the apparatus and method, so that others may be able to repeat the work.

The selection of methods employed in this investigation might be questioned by some who have had experience with reactions in moisture free media. For instance, the failure to use redistilled phosphorus pentoxide would seem to invalidate the results and conclusions. But arguments of this nature lose much of their force, when the fact is taken into consideration that both positive and negative results were obtained under working conditions that were as similar as it was possible to make them.

But another reason for confidence in the method lies in the fact that Baker has obtained similar results for ethyl alcohol and carbon tetrachloride. While no statement of his experimental methods has appeared, his results form the concluding paragraph of the Wilde lecture for 1909. ${ }^{1}$

"Mr. J. C. Thomson has recently done some experiments for me on the hydrogen sulphide and sulphur dioxide mixture. He finds that liquid alcohol and liquid sulphur dioxide (both having high specific inductive capacity) can bring about the decomposition in the mixture, while carbon tetrachloride, whose specific inductive capacity is low, is inert. Also, metallic aluminum and metallic mercury are apparently unable to affect the change."

While the dependence of chemical activity upon specific

${ }^{1}$ Mem. and Proc. Manchester Lit. and Phil. Soc., Vol. 53, Part III. 
inductive capacity is not expressly stated, it is certainly implied in Baker's statement. This is evidently the NernstThomson rule in a slightly modified form. In view of the work of Kahlenberg and Lincoln, ${ }^{1}$ Lincoln, ${ }^{2}$ and Schlundt, ${ }^{8}$ which proved that the Nernst-Thomson rule did not even hold qualitatively, much less quantitatively, it is surprising that Baker should attribute the ability of a liquid to induce the reaction in question, to its specific inductive capactiy.

In Table I there has been included the dielectric constants of the various liquids as given in the Landolt-Börnstein Tabellen (1905). A prediction from the specific inductive capacity would lead us far from the truth, if it is maintained that any liquid possessing a high dielectric constant will produce a reaction. For nitrobenzene, with a value of 36.45 and acetyl chloride (25.3) have no effect on the gaseous mixture, whereas either should act even better than the alcohols. Or, if the "rule" is modified to read "if any action occurs it will be caused by a liquid of high specific inductive capacity," then ether, which has a low value (4.3) forms an important exception. Nor do the esters employed have very high values; but the accuracy of the observations upon them in this investigation might be questioned, on the score of the ready decomposition of esters upon distillation. Moreover, it is not quite clear just where to draw the line between a high and a low dielectric value. Cases in point are ethyl chloride (6.29) and ethyl disulphide (7.2).

That association in the liquid state cannot be a determining factor is clearly seen from the last column of the table. Most of these values are taken from the work of Ramsay and Shields. Liquids, such as ether and benzaldehyde, which are unassociated, and methyl ethyl ketone, which is slightly so if at all, are capable of affecting the mixture. Moreover, Baker found that liquid sulphur dioxide, also an unassociated liquid, will induce the change.

\footnotetext{
1 Jour. Phys. Chem., 3, I2 (1899).

2 Ibid., 3, 457 (r899).

${ }^{3}$ Ibid., 5, I 57 (IgOI)
} 
Of late years there have been included under the term "catalysis," many phenomena of apparently different character. So the influence of traces of moisture or other substances upon chemical reactions has been commonly ascribed to catalytic action. But this is no satisfactory explanation of the process, for it does not help us at all in gaining a cleater insight into the mechanism of chemical change. What essential difference is there between the action of ammonia and hydrochloric acid gases in the presence of a trace of moisture, and the neutralization of ammonium hydroxide by a solution of hydrochloric acid? In the latter case water is just as much a catalyzer as in the former. A satisfactory theory of catalysis will apply equally well as a theory of solutions and vice versa.

From the study of reactions involving pure substances, there has arisen the idea that pure compounds cannot react except in the presence of a suitable additional reagent. The function of the solvent, according to the theory of electrolytic dissociation would be to separate the reacting substances into ions. However, Kahlenberg ${ }^{1}$ has demonstrated that instantaneous actions may proceed in non-ionizing media. Armstrong too, has always contended that the function of the solvent was not to dissociate but to associate; not to separate substances into ions, but to build them into complexes. The following quotation from one of his papers gives Armstrong's ${ }^{2}$ views on the subject.

"Regarding the problem from the standpoint of Faraday's electrolytic studies, and in view of the well-known observations of De la Rive, Brereton Baker, Cowper, and Dixon, I assume, however, that no two molecules can interact directly; that in all cases of chemical interchange (including electrolysis) the necessary slope of potential can only be provided by the inclusion of the interacting substances in a triple or tripartite conducting system."

The assumption that "no two molecules can interact

1 Jour. Phys. Chem., 6, I (1902).

2 Proc. Roy. Soc., 8r, 83 (1908). 
directly" is not warranted by the facts as we know them at present. Even in the case of the system, hydrogen sulphide and sulphur dioxide, Baker maintains that liquid sulphur dioxide can induce the reaction.

But the question of the possibility of the direct interaction of two molecules, in no way affects the idea that the solvent enters into combination with the solutes in cases of chemical action. On this basis, the liquid would form intermediate compounds with the hydrogen sulphide and sulphur dioxide, which subsequently would rearrange to produce the final products. Now, as to the nature of these intermediate compounds, it is not necessary that they conform to the law of definite proportions. Slowly the idea of compounds in varying proportions is gaining favor. Nor is it to be expected that the intermediate compounds be prepared step by step in the order of their occurrence during a reaction, for our methods of isolation of substances are such as would continually change the composition of the intermediate compounds.

It is therefore assumed, that the liquids which induced the reaction between hydrogen sulphide and sulphur dioxide, entered into a loose chemical combination with the gases; that in those cases, in which the organic liquid was unable to initiate the chemical change, no such loose combination occurred. Many examples of the action of hydrogen sulphide or sulphur dioxide upon the organic liquids employed in this investigation are recorded in Beilstein. The contention is not made that these compounds are intermediary in the reactions reported in this paper. They are inserted merely to emphasize the possibility of chemical combination between the gases and the liquid. Nitriles unite with hydrogen sulphide to form thioamides, $\mathrm{CH}_{3} \mathrm{CN}+\mathrm{H}_{2} \mathrm{~S}=\mathrm{CHCSNH}_{2}$. Aldehydes exchange their oxygen for sulphur. $\mathrm{C}_{8} \mathrm{H}_{6} \mathrm{CHO}+\mathrm{H}_{2} \mathrm{~S}=$ $\mathrm{C}_{8} \mathrm{H}_{5} \mathrm{CHS}+\mathrm{H}_{2} \mathrm{O}$. Addition compounds may also form. $\mathrm{RCHO}+\mathrm{H}_{2} \mathrm{~S}=\mathrm{RCH}\langle\mathrm{OH}$

Both aldehydes and ketones form addition products with salts of sulphurous acid, so it is likely that they would 
possess some attraction for sulphur dioxide. In fact, Bössneck $^{1}$ has shown that sulphur dioxide enters into loose combination with acetone. Aldehydes are capable of similar action. Carvone yields a well defined crystalline product with hydrogen sulphide ${ }_{2} \mathrm{C}_{10} \mathrm{H}_{14} \mathrm{O} . \mathrm{H}_{2} \mathrm{~S}$. In the case of the alcohols, it is clearly the specific properties of the hydroxyl group that come into play. Whatever rôle is assigned to water, would apply equally well to the alcohols.

\section{Summary}

The main points contained in this paper are:

I. An apparatus has been devised by means of which the effect of organic liquids upon the interaction of the gases, hydrogen sulphide and sulphur dioxide, could be determined.

2. Water in its ability to accelerate chemical change is in no way exceptional or unique, since other liquids have been found that have the same power. Of those investigated, the following induce the reaction: ethyl, isobutyl and isoamyl alcohols; acetone; methyl ethyl ketone; acetonitrile; propionitrile; valeronitrile; benzyl cyanide; methyl benzoate, propyl acetate; isobutyl acetate; ether; benzaldehyde and carvone.

3. Some liquids are unable to accelerate the action. Of the liquids investigated, the following produced no action: carbon bisulphide; ethyl disulphide; benzol; amylene; chloroform; carbon tetrachloride; ethyl chloride; acetyl chloride; benzoyl chloride and nitrobenzene.

4. There is no rigorous parallelism between the specific inductive capacity or the association of the liquid solvent on the one hand and its ability to induce action on the other.

5. A rational explanation of the phenomena lies in the view that chemical action occurs through the formation of intermediate compounds.

This investigation was carried out under the supervision of Professor Kahlenberg. I take this means of acknowledging my obligations for his interest in the work, and also for his generosity in placing at my disposal his private collection of chemicals.

University of Wisconsin,

June, Igro

${ }^{1}$ D. R. Pat. 47093 , Ber. chem. Ges. Berlin, 22, c; 303 (1889). 